\title{
Stock Assessment of Small Pelagic Fishes Caught by Ring Net Fishery in the Camotes Sea, Central Visayas, Philippines (2003-2012)
}

\author{
Prudencio B. Belga, Jr. ${ }^{1}$, Bruna T. Abrenica ${ }^{1, \star}$, Johnson S. Paran ${ }^{1}$, Regina Therese Bacalso ${ }^{2}$ \\ ${ }^{1}$ Bureau of Fisheries and Aquatic Resources Region VII, Arellano Blvd., Cebu City \\ ${ }^{2}$ ECOFISH Project, Cebu Technical Office, 6F CIFC Towers, North Reclamation Area, Cebu City 6000
}

\section{A B S T R A C T}

An analysis of the ten-year data on catch, effort, and length frequency of small pelagic caught from ring net fishery in the Camotes Sea was made. Length frequency data were used to estimate growth, mortality (total, natural, and fishing mortalities) and exploitation levels using the FAO-ICLARM Fish Stock Assessment Tools (FISAT) program developed by FAO/ICLARM.

Generally, the sizes of the major species caught from ring net fishery are smaller than the maximum size they can attain and were harvested before reaching maturity lengths. The probability of capture at $\mathrm{L}_{50}$, however, was higher in 2003-2012 than in 1983-1987 assessment.

Analysis of the recruitment pattern in the Camotes Sea reveals a dual recruitment mode per year starting from April to June which conforms to the findings of Jabat and Dalzell (1988) of which bimodal pattern of recruitment was observed for most of the small pelagic species in the catch of the ring net fishery from the Camotes Sea and in the Philippines in general.

Exploitation rate $(\mathrm{E}=\mathrm{F} / \mathrm{Z})$ estimates of three dominant pelagic species, Decapterus macrosoma $\left(\mathrm{L}_{\infty}=27.56\right.$ and present $\left.\mathrm{E}=0.71\right)$, Selar crumenophthalmus $\left(\mathrm{L}_{\infty}=30.03 \mathrm{~cm}\right.$ and present $\left.\mathrm{E}=0.68\right)$, and Decapterus kurroides $\left(\mathrm{L}_{\infty}=41.64\right.$ and present $\left.\mathrm{E}=0.51\right)$ revealed they are vulnerable to ring net fishery as exhibited by high $\mathrm{E}$ values exceeding the 0.5 threshold. The present exploitation levels suggest growth overfishing of these pelagic species which will eventually lead to unsustainable ring net fishery in the Camotes Sea.

*Email: ronaabrenica70@gmail.com

Keywords: stock assessment,

Received: 27 May 2017

Accepted: 22 October 2017

\section{I N T R O D U C T I O N}

$\mathbf{T}$ he Camotes Sea is one of the most important fishing grounds in the Visayan region. The area is surrounded by 11 municipalities and 4 chartered cities namely Lapu-Lapu City, Mandaue City, Consolacion, Liloan, Compostela, Danao City, Carmen, Catmon, Borbon, Tabogon, Bogo City, San Francisco, Poro, Tudela, and Pilar.

Majority of the fisherfolks were full-time fishers with monthly income from fishing ranging from Php 1,000-6,000 for the marginal fishers to Php 20,000100,000 for the commercial fishers. About half of the fisherfolks earned Php 1,000-3,000 per month, while others were fishing for consumption only with an average monthly income of Php 2,700. Both motorized and nonmotorized boats are utilized in most fishing activities except in the gathering of sea cucumbers and shells.

The growing importance of ring net fishing in the Camotes Sea has given rise to many speculations regarding its effect on the fishery resources. Most of the marginal fishermen, for instance, believe that the rapid increase in the number of commercial fishing activities that catch small pelagic fishes in the Camotes Sea would, in the long run, lead to the depletion of these fishery resources if not properly regulated.
In any fishery investigation, information on stock assessment is deemed necessary, particularly to commercially important species of fish. Information on sexual maturation and sex ratio of many ring net caught fishes in the Camotes Sea is, however, inadequate and hence an attempt has been made to study this aspect of fishery biology in the Camotes Sea. This report presents the findings using the data gathered by NSAP Region 7 on the catch trends of the commercial ring net fishery in the Camotes Sea from 2003-2012, and the population dynamics and exploitation rates of the major fish resources exploited by this fishery. The results are then compared to the findings in an earlier study by Jabat and Dalzell (1988) of the Danao ring net fishery from 19831987.

\section{METHOD OLO G Y}

\section{Study site}

The Camotes Sea is located approximately at longitudes $124^{\circ} 45^{\prime} \mathrm{E}$ and latitudes $10^{\circ} 55^{\prime} \mathrm{N}$. The area is bounded to the north by the Ormoc Bay and the Visayan Sea, to the east by the island of Leyte, to the south by the Danajon Bank of Bohol, and to the west by the island of Cebu. At its center is the Camotes Island (Figure 1). The 


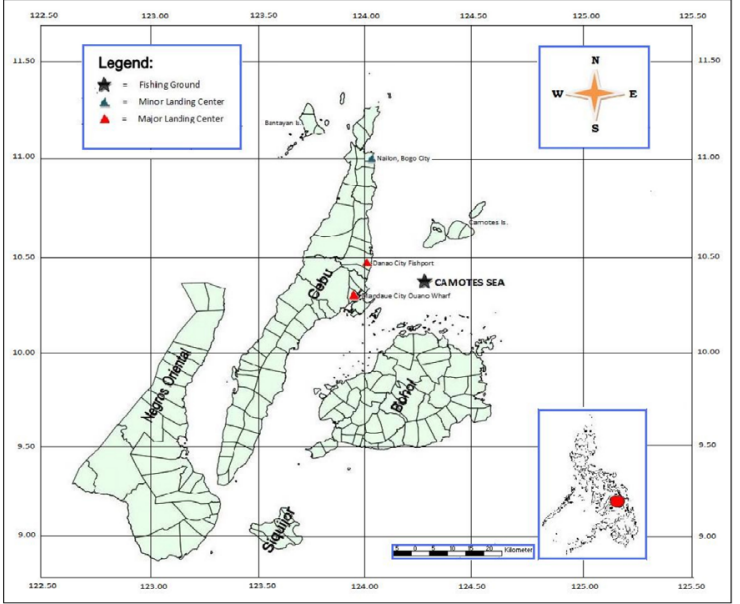

Figure 1. Gridded map of Central Visayas showing the landing centers of ring net fishery in Camotes Sea.

Camotes Sea covers a total area of 10,900 sq. km. The deep off shelf covers $9,500 \mathrm{sq}$. $\mathrm{km}$. with depths of 10-800 m. The southern portion of the northern coast of Bohol has a shelf area that covers about 1,400 sq. km. with depths ranging from $14-700 \mathrm{~m}$.

\section{Sampling site}

Monitoring of landed catch was conducted in the two major commercial fish landing sites in Danao City. Danao City fish landing area is one major landing site in the Cebu Province. In this area, there were 179 fishing boats monitored by NSAP enumerators from 2003-2012 and $83 \%$ were ring nets, $5 \%$ purse seines, $9 \%$ gillnets, and $3 \%$ were hook and line.

\section{Data collection}

Five (5) enumerators were hired and trained to monitor the daily catch landings of ring nets, gillnets, purse seines, and hook and line fishing gears from 20032012. The sampling scheme involved monitoring the landed catch for two successive days followed by a oneday interval, for an average of 22 sampling days a month. Data were recorded in prepared forms that included the following information:

a. Name of the fishing ground

b. Landing center

c. Date of sampling

d. Name of boats

e. No. of fishing days of the actual operation (time)

f. Total catch by boat (no. of boxes/bañeras or weight in $\mathrm{kg}$ )

g. Catch sample weight $(\mathrm{kg})$

h. Catch composition (scientific names of the marine species)

i. Name and signature of samplers/recorders

Data on the fishing boat, its propulsion, gross tonnage, and other relevant information were obtained via actual interviews with the fishermen. Fish samples were sorted by species, and their sample weights recorded. Fish lengths were measured in centimeters to the lower $\mathrm{cm}$ limit, while weight measurements were in kilograms.

\section{Data processing and analysis}

All data were submitted to the NSAP office in Cebu City for processing and encoding. All catch, effort, species composition, and length frequency data from the monitored landed catch of the commercial ring net operations were consolidated by month for every year into the sampling. Annual fish data were processed and analyzed using the FISAT program developed by FAO/ ICLARM.

Catch landings from gillnets and hook and lines were also monitored by the enumerators during the study period. However, because of the very limited number of landings by these municipal fishing gears at the Looc and Tabuk Looc sampling stations, their yield estimates were deemed not representative for the entire Camotes Sea municipal fisheries production. Consequently, they were not included in the analysis.

\section{Catch per unit effort (CPUE) and yield estimates}

The catch per unit effort (CPUE) was standardized to kg per hour of operation. The calculated mean CPUE $(\mathrm{kg} / \mathrm{hr})$ and the total number of fishing trips made within the month, converted into total fishing hours, were used to estimate the total landed catch of the fishery on a monthly basis. Annual production estimates were simply the sum of the computed total monthly yields. Sample weights of the fish species were raised to the total catch per fishing trip as follows:

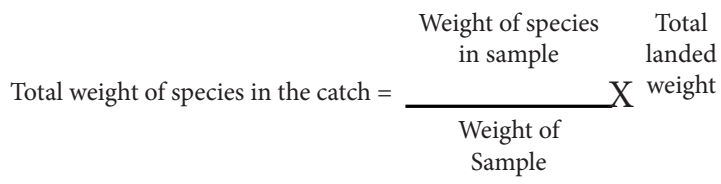

Total catch per month for each species by gear type was estimated using the total number of fish landings by gear per month against the number of landings sampled as raising factor. Monthly estimates were then consolidated to calculate the annual landings for a particular fish species by gear type. Similarly, for the length distribution of the total catch by species for each month, a raising factor was used:

$$
\text { R.F. }=\frac{\text { Total monthly catch of species }}{\text { Sample weight of species }}
$$

\section{Catch composition and dominant species in the catch}

The dominant fish species caught were determined based on the fishes' contribution by weight to the total harvest from 2003-2012. All fish species were then arranged through percentage ranking by order of 
highest to lowest contribution to the total catch.

\section{Seasonality of selected major species}

The mean monthly catch per unit effort (kg/ hr) was computed for the 10-year data in an attempt to determine the seasonality of the commercial ring net fishery in the Camotes Sea as a whole, and of the major fishery species in the catch.

\section{Estimating growth and mortality of major species using L-F data}

Monthly length frequency data were processed using the computer program FISAT (Gayanilo and Pauly 1997) to determine the exploitation rate.

The von Bertalanffy growth parameters $\mathrm{L}_{\infty}$ and K were estimated first using the Powell-Wetherall method (Wetherall 1986) to approximate the asymptotic length $\left(\mathrm{L}_{\infty}\right)$ and the ratio of the coefficients of mortality and growth $(\mathrm{Z} / \mathrm{K})$. Verification and final selection of growth parameters were carried out with the Electronic Length Frequency Analysis (ELEFAN I ) routine.

The final values of $\mathrm{L}_{\infty}$ and $\mathrm{K}$ were used to calculate the length converted catch curve (Pauly 1984) in order to derive estimates of the instantaneous total mortality $(\mathrm{Z})$. Further, estimates of natural mortality $(\mathrm{M})$ were derived from the empirical equation given by Pauly (1980):

$\log 10 \mathrm{M}=-0.0066-0.279 \log 10 \mathrm{~L}_{\infty}+0.6543 \log 10 \mathrm{~K}+0.4634 \log 10 \mathrm{~T}$

where $\mathrm{L}_{\infty}$ and $\mathrm{K}$ are the VBGF growth parameters and $\mathrm{T}$ is the annual mean habitat temperature $\left({ }^{\circ} \mathrm{C}\right)$ of the water in which the stock in question lives. For this study, the temperature value used was $28.3^{\circ} \mathrm{C}$, which is the mean surface water temperature for the Philippines as a whole (Dalzell and Ganaden 1987). Furthermore, the fishing mortality $(\mathrm{F}=\mathrm{Z}-\mathrm{M})$ and exploitation $(\mathrm{E}=\mathrm{F} / \mathrm{Z})$ rates were obtained.

\section{RESULT S}

\section{Fishing gear/Boat inventory}

The numbers of commercial and municipal fishing gears operating in the Camotes Sea as of 2002 are shown in Table 1. The DA-BFAR 7 Fisheries Licensing Section registered 26 commercial ring nets and 2 commercial purse seiners operating in the Camotes Sea. At the same time, there were a total number of 18,754 municipal fishing gears, based on the records provided by the municipal fisheries technicians. These municipal fishing gears included several gillnet and handline variations, jigs, and spears. The major municipal fishing gear types were the multiple handlines, followed by the hook and line, squid jigs, and gillnets. These four major gear types are common in all 11 municipalities surrounding the Camotes Sea.
Table 1. Inventory of municipal fishing gears operated in the Camotes Sea (AY2002).

\begin{tabular}{ccc}
\hline Category & Fishing Gear & Count \\
\hline Commercial & Ring net & 26 \\
Sub-total & Purse seine & 2 \\
& & 28 \\
Municipal & Multiple handline & 4,380 \\
& Hook and line & 3,695 \\
& Squid jig & 1,783 \\
& Gill net & 1,737 \\
& Troll line & 1,258 \\
& Bottom set gillnet & 1,810 \\
& Spear fishing & 694 \\
& Bottom set long line & 586 \\
& Fish jig & 575 \\
& Drift long line & 505 \\
& Others & 2,731 \\
Sub-total & & 18,754 \\
\hline Grand total & & $\mathbf{1 8 , 7 8 2}$ \\
\hline
\end{tabular}

\section{Yield Estimates and Catch per Unit Effort (CPUE)}

Landed catch of commercial ring nets were monitored at the Looc and Tabuk Looc landing centers in Danao City, Cebu from 2003-2012. The total annual yield (metric ton) and total boats landed monitored from commercial ring nets in the Camotes Sea over the 10 year period are shown in Figure 2. The comparative trend of total annual yield seemed to exhibit an erratic pattern. Notably, 2011 recorded the highest catch $(1,753 \mathrm{MT})$ with lower boat landings $(1,195)$ as compared to 2003 where production is low $(1,250 \mathrm{MT})$ with highest boat landings $(2,340)$. The overall production of Camotes Sea cannot be estimated since there was no updated data on boat and gear inventory available during the assessment period.

The monthly mean CPUEs per year expressed in $\mathrm{kg} / \mathrm{hr}$ were computed to obtain information on the catch rate per operation is presented in Table 2. The CPUE values vary between months and years.

To find out if there are changes in the seasonality of catch over time, the mean monthly CPUEs $(\mathrm{kg} / \mathrm{hr})$ for ten years of the commercial ring nets in the Camotes Sea were computed and presented in Figure 3. The monthly trend of production for the ten year period showed two distinct patterns.

In the early part of the year, CPUE rates had increased starting from January (313), and reach its highest peak in April (446 kg/hr). However, a declining trend was noted in May (399), June (379), and the lowest rate in July (252). On the other hand, in the later semester of the year, the catch rate showed a secondary peak beginning August (293) which carry on until December (380) obtaining the major peak.

\section{Species composition}

A total of 57 species belonging to 18 families and four (4) unidentified were recorded from ring net fishery 
Table 2. Monthly mean catch per unit effort (CPUE kg/hr) for the Camotes Sea ring net fishery from 2003-2012.

\begin{tabular}{ccccccccc}
\hline Month $\backslash$ Year & $\mathbf{2 0 0 3}$ & $\mathbf{2 0 0 4}$ & $\mathbf{2 0 0 5}$ & $\mathbf{2 0 0 6}$ & $\mathbf{2 0 0 7}$ & $\mathbf{2 0 1 0}$ & $\mathbf{2 0 1 1}$ & $\mathbf{2 0 1 2}$ \\
\hline January & 299.78 & 374.19 & 324.07 & 183.67 & 376.94 & 515.4 & 249.2 & 187.64 \\
February & 258 & 417.37 & 137.88 & 227.74 & 471.9 & 202.6 & 423.24 & 282.51 \\
March & 395.52 & 380.38 & 402.09 & 325.23 & 430.5 & 500.5 & 509.92 & 441.85 \\
April & 280.86 & 221.14 & 451.84 & 420.97 & 476.12 & 634.67 & 586.6 & 501.33 \\
May & 208.01 & 334.95 & 416.52 & 262.14 & 413.63 & 470.66 & 494.24 & 595.79 \\
June & 244.46 & 376.65 & 443.43 & 274.43 & 491.67 & 367 & 265.92 & 575.79 \\
July & 175.92 & 276.62 & 213.27 & 209.89 & 353.88 & 254.68 & 239.6 & 295.15 \\
August & 138.53 & 267.3 & 282.24 & 225.85 & 521.3 & 243.13 & 318.12 & 349.65 \\
September & 163.06 & 158.73 & 366.96 & 332.1 & 476.82 & 228.1 & 300.23 & 344.5 \\
October & 194.93 & 123.21 & 405.56 & 279.73 & 393.5 & 278.43 & 355.04 & 286.54 \\
November & 229.34 & 176.97 & 294.75 & 273.45 & 203.2 & 376.42 & 663.84 & 312.14 \\
December & 314.89 & 388.68 & 392.53 & 300.25 & 531.2 & 300.2 & 322.3 & 489.67 \\
\hline
\end{tabular}

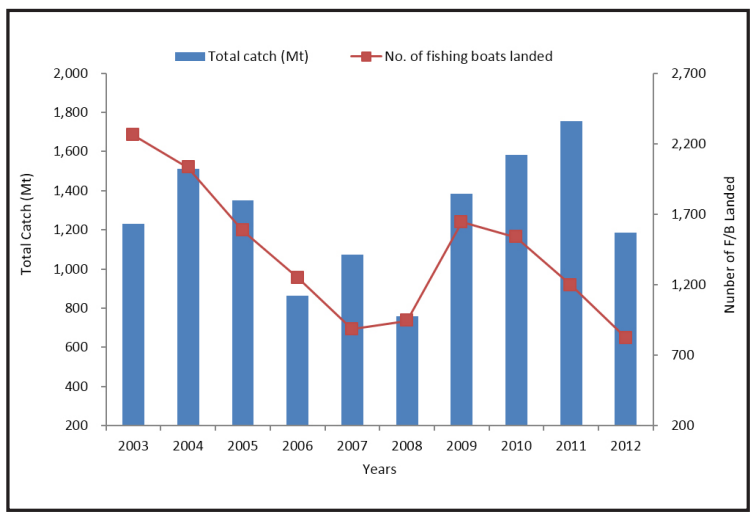

Figure 2. Total annual catch (tons) from ring net fishery in Camotes Sea from 2003-2012.

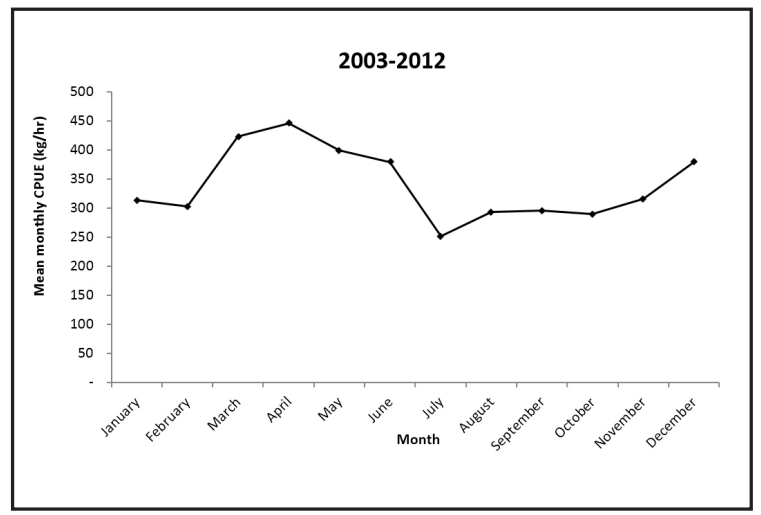

Figure 3. Monthly mean CPUE (kg/hr) of commercial ring net in Camotes Sea from 2003-2012.

in the Camotes Sea from 2003-2012. The dominant fish species caught by habitat type are mainly small pelagics. The percentage share based on the volume of catch landed of the top five dominant species is computed and presented in Figure 4. Topping the rank is Decapterus tabl (28\%), followed by Decapterus macrosoma (19\%), Selar crumenophthalmus (15\%), Decapterus kurroides (8\%), and Mene maculata (7\%) having the lowest share. The five major species comprise about $77 \%$ of the average total volume of the catches of the ring net fishery monitored

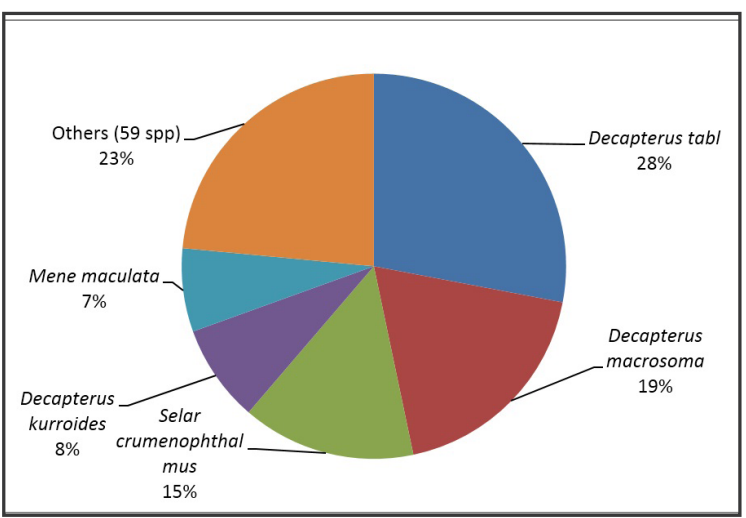

Figure 4. Relative abundance (\%) of top five species based on volume of landed catch from ring net fishery in Camotes Sea from 2003-2012.

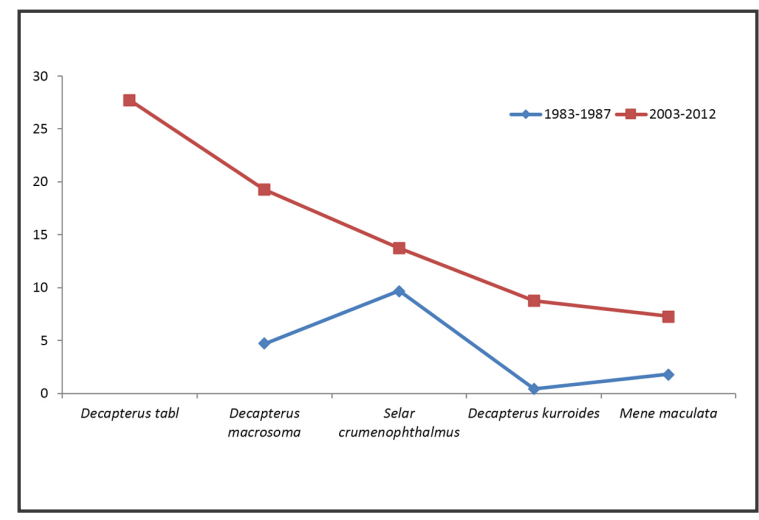

Figure 5. Comparative trend of mean relative abundance (\%) of top dominant pelagic species caught from ring net fishery in Camotes Sea from in 1983-1987 (Jabat and Dalzell 1988) and 2003-2012 (this study).

over 10 year period in the Camotes Sea (Table 3). Comparing the present abundance of major species with that of the catches collected between 1983-1987 (Jabat and Dalzell 1988) showed a marked difference in species composition (Figure 5).

The recent catch is dominated by Decapterus tabl which is not present in the earlier study. There is a shift in the dominance of small pelagics accounted for between the two studies conducted for ring net fishery in 
Table 3. Top five (5) dominant species by percentage weight of catch from ring net fishery in Camotes Sea monitored from 2003-2012.

\begin{tabular}{|c|c|c|c|c|c|c|c|c|c|c|c|}
\hline Species & 2003 & 2004 & 2005 & 2006 & 2007 & 2008 & 2009 & 2010 & 2011 & 2012 & Mean \\
\hline Decapteus tabl & 30.88 & 27.62 & 15.24 & 22.95 & 37.19 & 21.67 & 21 & 31 & 32.39 & 37 & 27.69 \\
\hline $\begin{array}{l}\text { Decapterus mac- } \\
\text { rosoma }\end{array}$ & 21.75 & 30.34 & 41 & 13.25 & 15.41 & 30.5 & 15 & 6.77 & 6.43 & 12.39 & 19.28 \\
\hline $\begin{array}{l}\text { Selar crumenoph- } \\
\text { thalmus }\end{array}$ & 6.89 & 9.84 & 5.43 & 10.19 & 2.8 & 9.59 & 26.74 & 23.45 & 20.59 & 22 & 13.75 \\
\hline $\begin{array}{l}\text { Decapterus kur- } \\
\text { roides }\end{array}$ & 5.43 & 4.97 & 3.47 & 10.28 & 7.72 & 16.61 & 8.07 & 9.19 & 13.03 & 8.64 & 8.74 \\
\hline Mene maculata & 5 & 5.62 & 5.85 & 15.97 & 12.91 & 4.85 & 4.04 & 7.92 & 6.95 & 3.64 & $\begin{array}{c}7.28 \\
76.74 \% \\
\end{array}$ \\
\hline Others & 21.66 & 21.55 & 16.24 & 27.34 & 21.59 & 15.31 & 20.87 & 21.62 & 20.57 & 15.54 & 23.13 \\
\hline
\end{tabular}

the Camotes Sea, 1983-1987 by Jabat and Dalzell (1988) and 2003-2012 (this study). The by-catch observed in the earlier assessment is now dominating the catch of ring net fishery in the study area.

\section{Seasonality of dominant species}

Seasonality of dominant catch was determined based on abundance (in volume) and occurrence (frequency) of five fish species from the ring net fishery in the Camotes Sea monitored from 2003 to 2012.

In consonance with the bimodal trend in overall yield and catch rates, the monthly mean CPUEs of the top species Decapterus tabl exhibits two patterns, the primary peak was observed in February and April, and the secondary distinct peak occurred in December (Figure 6A). The highest peak of Decapterus macrosoma also occurred in April which prevailed until June but dropped in July. However, no more secondary peak was noted thereafter (Figure 6B). The production rate of Selar crumenophthalmus seemed lower in the first semester

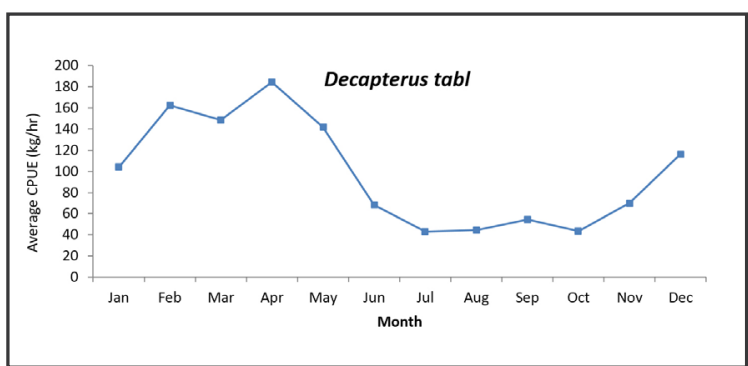

Figure 6A. Seasonality of catch (CPUE kg/hr) of Decapterus tabl caught by ring net fishery in Camotes Sea from 2003-2012.

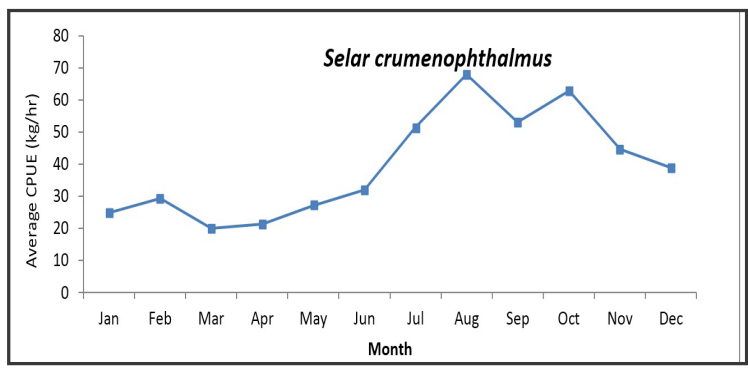

Figure 6C. Seasonality of catch (CPUE kg/hr) of Selar crumenophthalmus caught by ring net fishery in Camotes Sea from 2003-2012. of the year until it started to increase in May, peaked in August and October and declined in November to December (Figure 6C). In contrast, the catch rate (CPUE $\mathrm{kg} / \mathrm{hr}$ ) of Decapterus kurroides showed a slight increase in the beginning of the year but steadily decreases from February to July and shoot up again in August, September, November and obtaining the highest peak in December (Figure 6D). Of the five major catch, Mene maculata is the only pelagic species that does not belong to family Carangidae but also present in the previous study of Jabat and Dalzell (1988). As for this species, its production pattern is similar to $D$. kurroides where low catch rates were noted in the first semester with lowest CPUE rate in July, then gradually increases in August to September and reaching the highest peak in December. The highest production of both species (D. kurroides and M. maculata) occurred in December (Figure 6E).

\section{Length Frequency Distribution and Population Parameters}

Analysis of length frequency data of the top

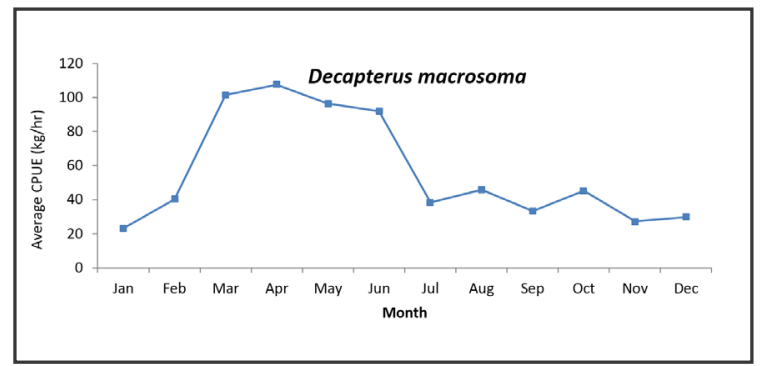

Figure 6B. Seasonality of catch (CPUE kg/hr) of Decapterus macroso$m a$ caught by ring net fishery in Camotes Sea from 2003-2012.

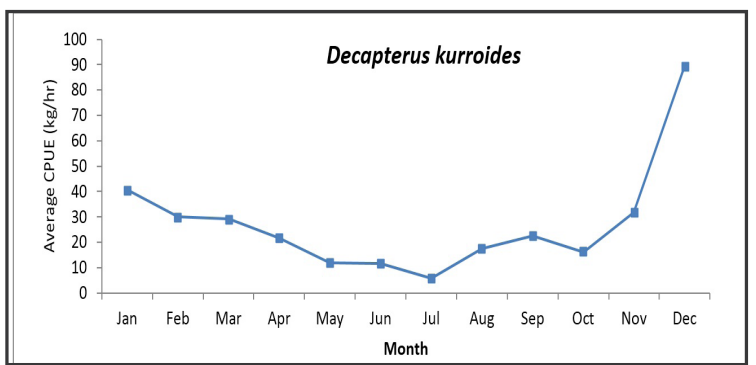

Figure 6D. Seasonality of catch (CPUE kg/hr) of Decapterus kurroides by ring net fishery in Camotes Sea from 2003-2012. 
Table 4. Total length (TL) in $\mathrm{cm}$ at sexual maturity of five dominant species caught by ring net fishery in

Camotes Sea from 2003 to 2012.

\begin{tabular}{lccc}
\hline \multirow{2}{*}{ Species } & \multirow{2}{*}{ Camotes Sea } & \multicolumn{2}{c}{ Fish Base 2008 version } \\
\cline { 3 - 4 } & & Common length & Maximum length \\
\hline Decapteus tabl & $16.5-27$ & 25 & 50 \\
Decapterus macrosoma & $19.4-26$ & 25 & 35 \\
Selar crumenophthalmus & $18.4-23$ & 30 & 60 \\
Decapterus kurroides & $20.2-34$ & 30 & 45 \\
Mene maculata & $13.7-21$ & 18 & 30 \\
\hline
\end{tabular}

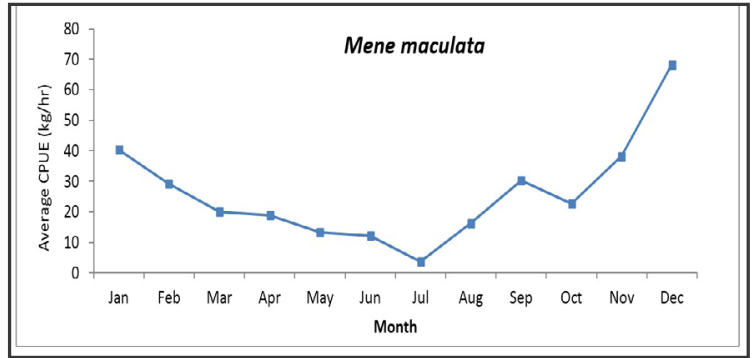

Figure 6E. Seasonality of catch (CPUE kg/hr) of Mene maculata by ring net fishery in Camotes Sea from 2003-ww2012.

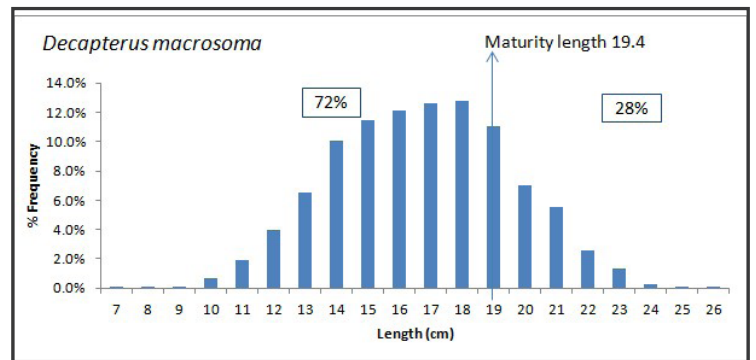

Figure 7B. Length frequency distribution of Decapterus macrosoma caught by ring net fishery in Camotes Sea from 2003-2012.

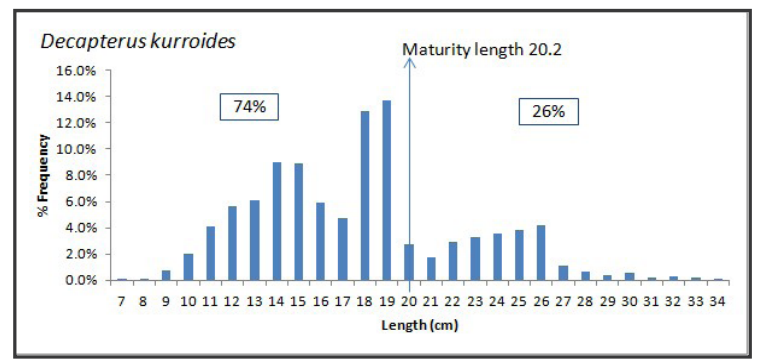

Figure 7D. Length frequency distribution of Decapterus kurroides caught by ring net fishery in Camotes Sea from 2003-2012.

five dominant species caught by ring net fishery in the Camotes Sea from 2003-2012 shows that at least 47\% to as high as $75 \%$ were in the $6-20 \mathrm{~cm}$ total length (TL) and beyond their maturity sizes. The TL size range for Decapterus tabl is $8-27 \mathrm{~cm}$; Decapterus macrosoma, 7-26 cm; Selar crumenophthalmus, 6-23 cm; Decapterus kurroides, 7-34 cm; and Mene maculata, 6-21 cm (Figures 7A-7E). Of the five species analyzed, D. $\operatorname{tabl}(53 \%)$ and $M$. maculata (67\%) have sizes that fell within their maturity lengths. Generally, it can be noted that sizes of small pelagic caught by ring net fishery in the Camotes Sea are much smaller than the maximum size these species can attain (Table 4).

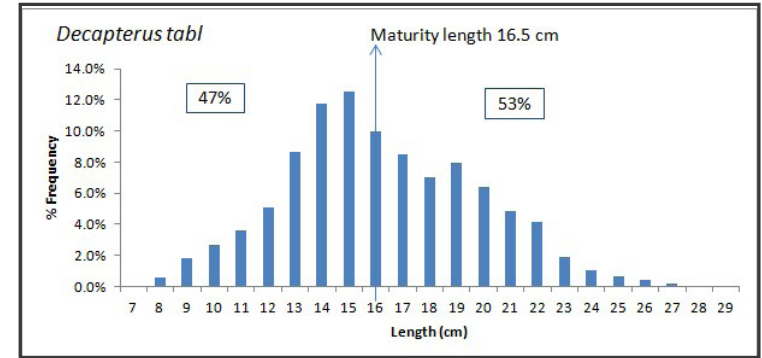

Figure 7A. Length frequency distribution of Decapterus tabl caught by ring net fishery in Camotes Sea from 2003-2012.

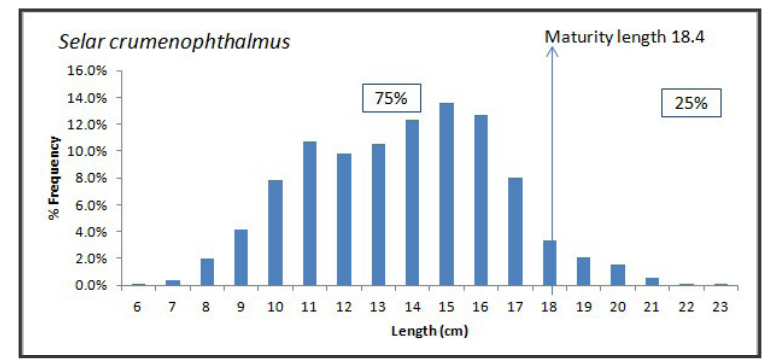

Figure 7C. Length frequency distribution of Selar crumenophthalmus caught by ring net fishery in Camotes Sea from 2003-2012.

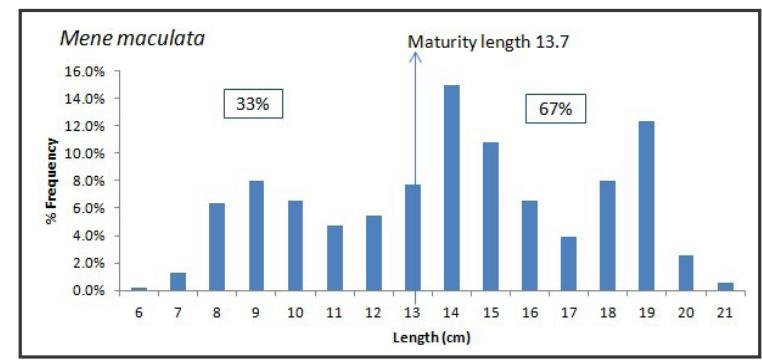

Figure 7E. Length frequency distribution of Mene maculata caught by ring net fishery in Camotes Sea from 2003-2012.

To determine the exploitation rate of the major species exploited by the ring net fishery, length frequency data from 2003-2012 for D. kurroides and D. macrosoma were each pooled and analyzed representing a single annual data set while $S$. crumenophthalmus was analyzed as large data set covering a 10 -year period. The resulting mortality parameters are compared with the available data in the earlier study of Jabat and Dalzell (1988) results of length frequencies and fitted curves analysis are shown in Figures 8A-8C while the length-converted catch curves are given in Figures 9A-9C.

Comparable to the findings generated in the earlier study of Jabat and Dalzell (1988), the length 
frequency data for the species in 2003-2012 also demonstrates possibly two cohorts that are recruited and grow annually in the fishery. D. tabl and D. kurroides, for instance, show consistency in seasonality of the catch as their production peak twice in a year.

Estimates of the overall exploitation rate of the three (3) major species D. macrosoma, D. kurroides and S. crumenohthalmus are illustrated in Figures 10A-10C. Generally, there is an increasing trend in the exploitation values of all the species analyzed. Except for D. kurroides in 2004 and 2005, all the E values generated over time

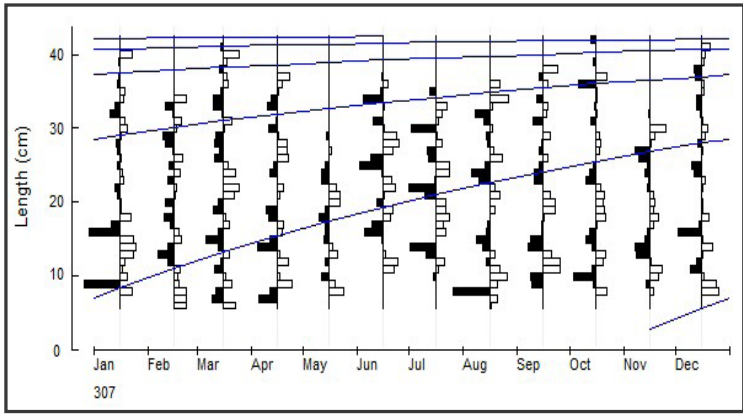

Figure 8A. Length frequency and fitted growth curves for $D$. kurroides, 2003-2012, compiled on a single annual basis, restructured by ELEFAN I. are above the 0.5 threshold which could be an indication that there is unsustainable ring net fishery in the Camotes Sea. Apparently, the high exploitation values obtained in this study is attributed to high total mortality $(\mathrm{Z})$ which is largely influenced by the remarkable increases in fishing mortality (F) higher than the mortality parameters observed in the earlier study (Table 5).

\section{Probabilities of Capture}

The probabilities of capture constructed from the catch curves of the three species D. kurroides, $D$.

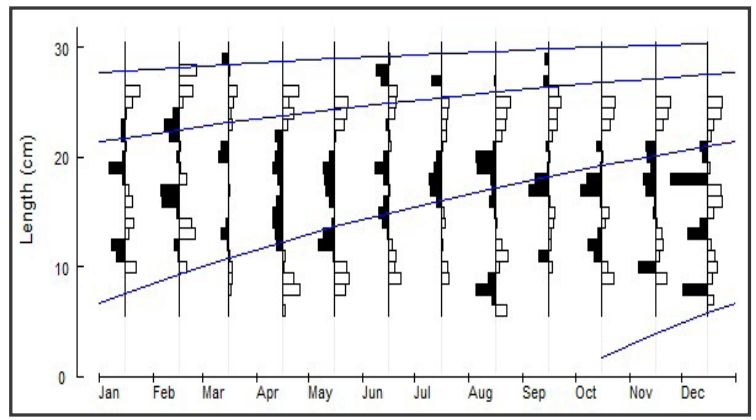

Figure $8 \mathrm{~B}$. Length frequency and fitted growth curves for D. macroso$m a, 2003-2012$, compiled on a single annual basis, restructured by ELEFAN I.
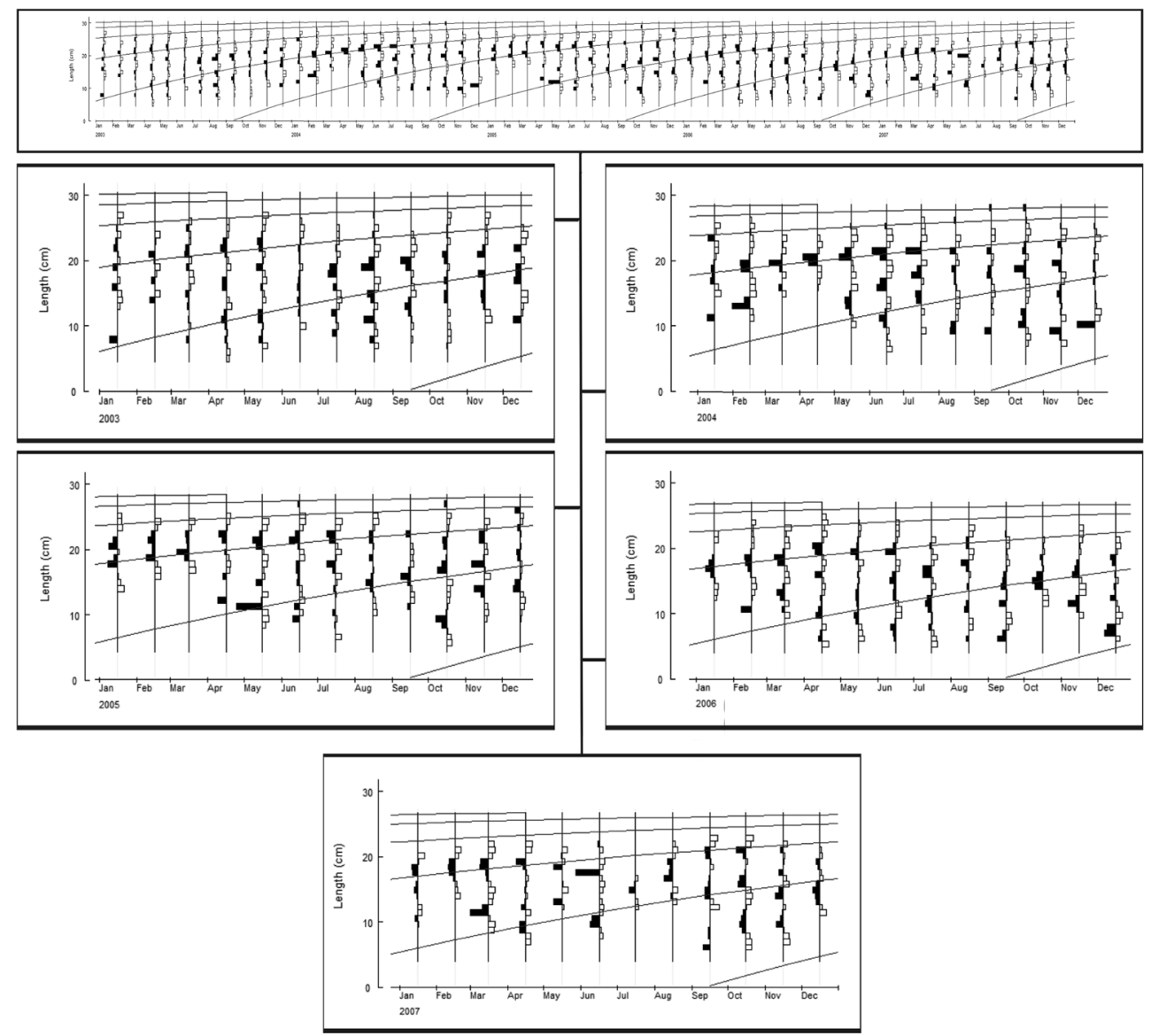

Figure 8C. Length frequency and fitted growth curves for S. crumenophthalmus, 2003-

2012, compiled on a single annual basis, restructured by ELEFAN I. 
Table 5. Comparison of growth and mortality parameters for Camotes Sea small pelagics from the ring net fishery for periods 1983-1987 and 2003-2012.

\begin{tabular}{|c|c|c|c|c|c|c|}
\hline \multirow{2}{*}{ Species } & \multicolumn{2}{|c|}{$\mathrm{L}_{\infty}(\mathrm{cm})$} & \multicolumn{2}{|c|}{$\mathrm{K}\left(\right.$ year $\left.^{-1}\right)$} & \multicolumn{2}{|c|}{$\mathrm{Z}\left(\right.$ year $\left.^{-1}\right)$} \\
\hline & '83-'87 & '03-'12 & '83-'87 & $03-12$ & '83-'87 & '03-'12 \\
\hline Decapterus macrosoma & 25.0 & 27.56 & 0.88 & 0.99 & 2.05 & 5.44 \\
\hline Selar crumenophthalmus & 28.8 & 30.03 & 0.86 & 0.89 & 3.52 & 4.35 \\
\hline Decapterus kurroides & - & 41.64 & - & 0.89 & - & 3.10 \\
\hline \multirow{2}{*}{ Species } & \multicolumn{2}{|c|}{$\mathrm{M}\left(\right.$ year $\left.^{-1}\right)$} & \multicolumn{2}{|c|}{$\mathrm{F}\left(\right.$ year $\left.^{-1}\right)$} & \multicolumn{2}{|c|}{$\mathrm{E}(\mathrm{F} / \mathrm{Z})$} \\
\hline & '83-'87 & '03-'12 & '83-'87 & '03-'12 & '83-'87 & '03-'12 - r r r \\
\hline Decapterus macrosoma & 1.73 & 1.56 & 0.32 & 3.88 & 0.16 & 0.71 \\
\hline Selar crumenophthalmus & 1.64 & 1.39 & 1.88 & 2.96 & 0.53 & 0.68 \\
\hline Decapterus kurroides & - & 1.52 & - & 1.58 & - & 0.51 \\
\hline
\end{tabular}

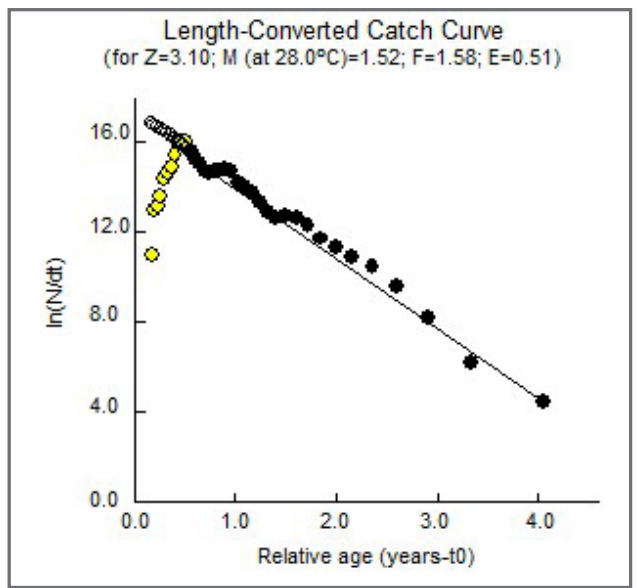

Figure 9A. Length converted catch curve for D. kurroides

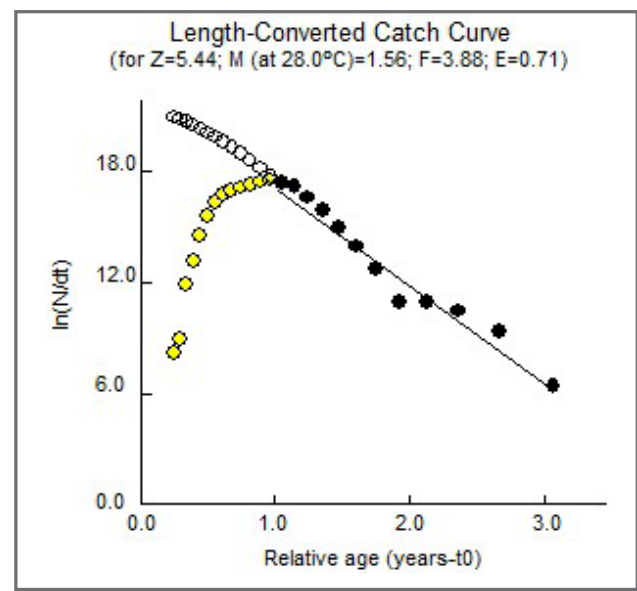

Figure 9B. Length converted catch curve for D. macrosoma (2003-2012)

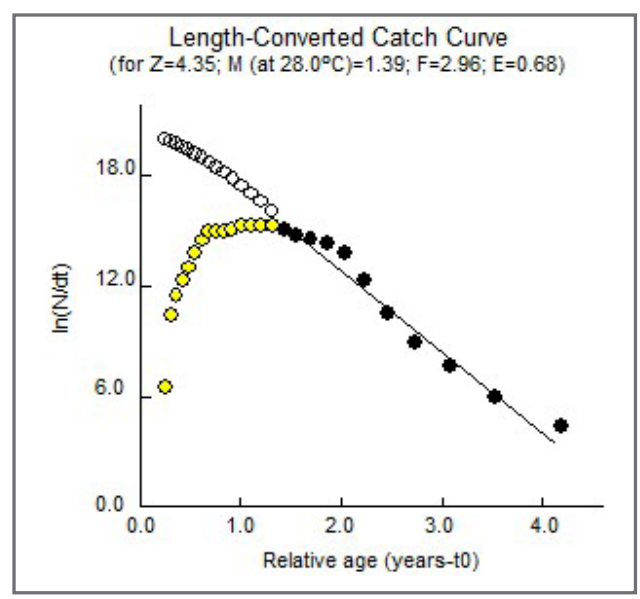

Figure 9C. Length-converted catch curve for Selar crumenophthalmus (2003-2012) 


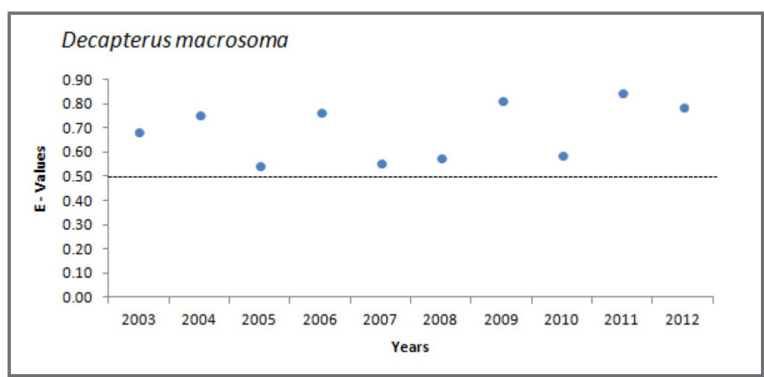

Figure 10A. Exploitation value E of Decapterus macrosoma caught by ring net fishery in Camotes Sea from 2003-2012.

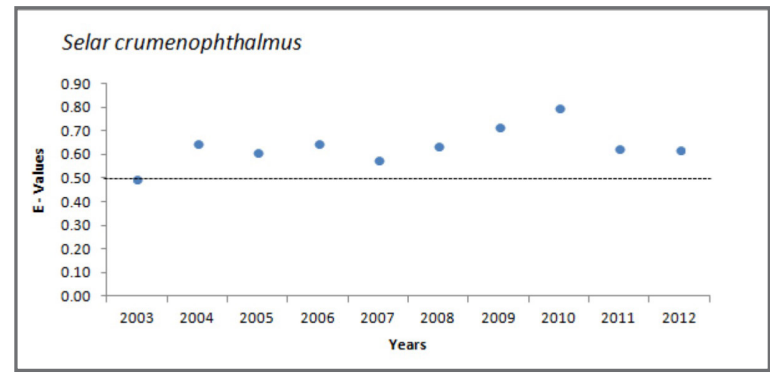

Figure 10B. Exploitation value E of Selar crumenophthalmus caught by ring net fishery in Camotes Sea from 2003-2012.

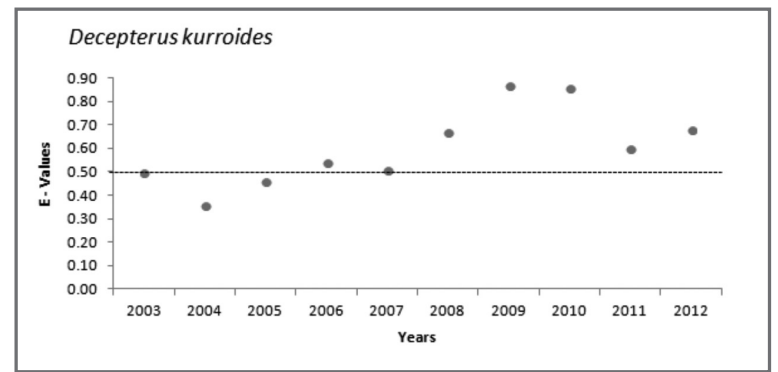

Figure 10C. Exploitation value E of Decapterus kurroides caught by ring net fishery in Camotes Sea from 2003-2012.

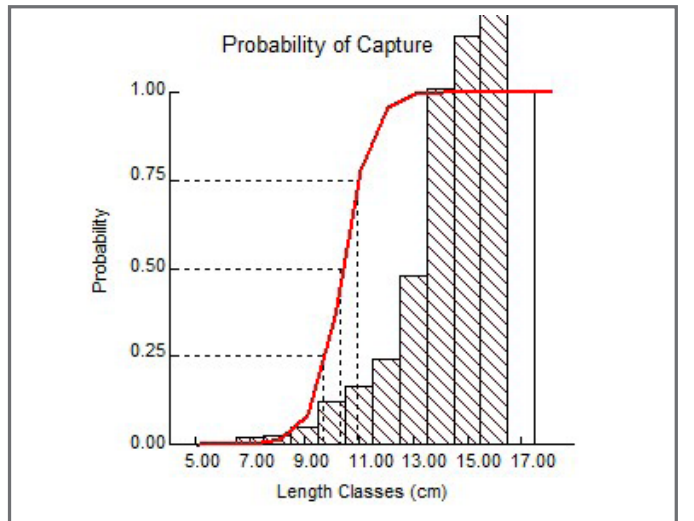

Figure 11A. Probability of capture for Decapterus kurroides caught by ring net fishery in Camotes Sea from 2003-2012.

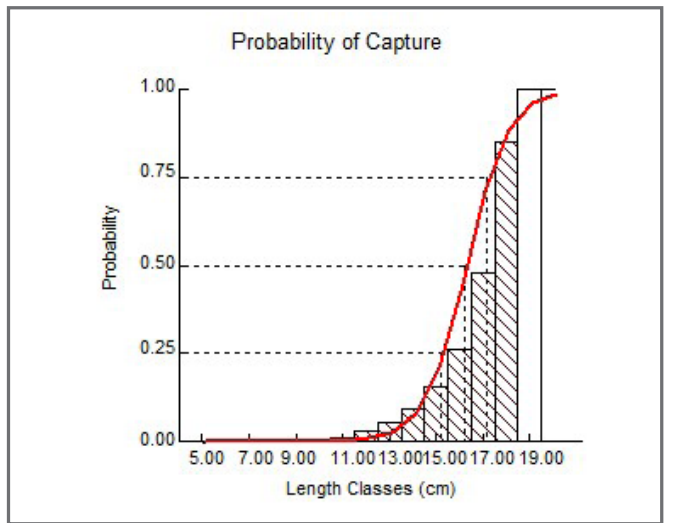

Figure 11B. Exploitation value E of Decapterus macrosoma caught by ring net fishery in Camotes Sea from 2003-2012.

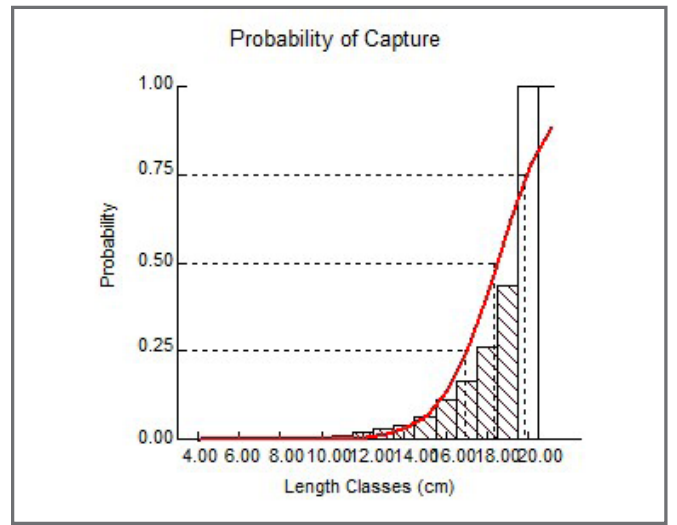

Figure 11C. Probability of capture for Selar crumenopthalmus caught by ring net fishery in Camotes Sea from 2003-2012. 
Table 6. Mean lengths at first capture (L50) in $\mathrm{cm}$ for the dominantly caught species from ring net fishery in Camotes Sea in 1983-1987 and 2003-2012.

\begin{tabular}{ccc}
\hline Species & $\mathbf{1 9 8 3 - 1 9 8 7}$ & 2003-2012 \\
\hline Decapteus tabl & - & - \\
Decapterus macrosoma & 12.9 & 16 \\
Selar crumenophthalmus & 17.8 & 18 \\
Decapterus kurroides & - & 10 \\
\hline
\end{tabular}

macrosoma and S. crumenophthalmus in the Camotes Sea commercial ring net fishery from 2003-2012 is shown in Figures 11A-11C. The resulting overall mean lengths at first capture of these species were compared with the values obtained in 1983-1987 (Table 6). Generally, it appears that the mean lengths of the capture of the major species in the catch are higher during the 2003-2012 period than during the 1983-1987 assessment.

\section{Recruitment pattern}

The recruitment pattern generated for $D$. kurroides, D. macrosoma, and S. crumenophthalmus in Camotes Sea show generally dual mode of recruitment for each year (Figures 12A-12C). This finding conforms with the results in Jabat and Dalzell (1988) where there is also a bimodal pattern of recruitment was observed for most of the small pelagic species in the catch of the ring net fishery from the Camotes Sea.

\section{D I S C US S I O N}

\section{Yield and Catch Per Unit Effort (CPUE)}

The comparative annual yield estimates (MT) of commercial ring nets monitored in the Camotes Sea from 2003 to 2012 showed an erratic trend. Production estimates vary with years and may be influenced by the number of boat landings but in no definite order. The highest yield was obtained in 2011 with lower boat landings. This would somehow indicate a productive 2011 compared to 2004 where catch yield is high with corresponding high boat landings. A more conservative and realistic understanding of the catch rate and trend

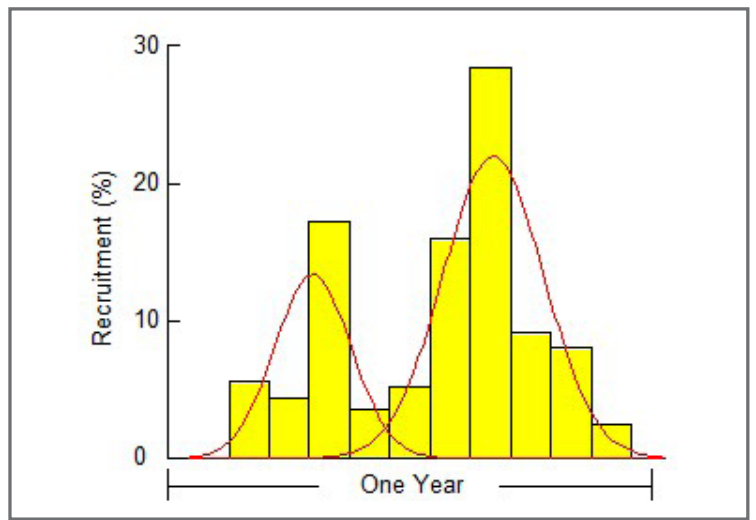

Figure 12A. Recruitment pattern for Decapterus kurroides caught by ring net fishery in Camotes Sea from 2003-2012.

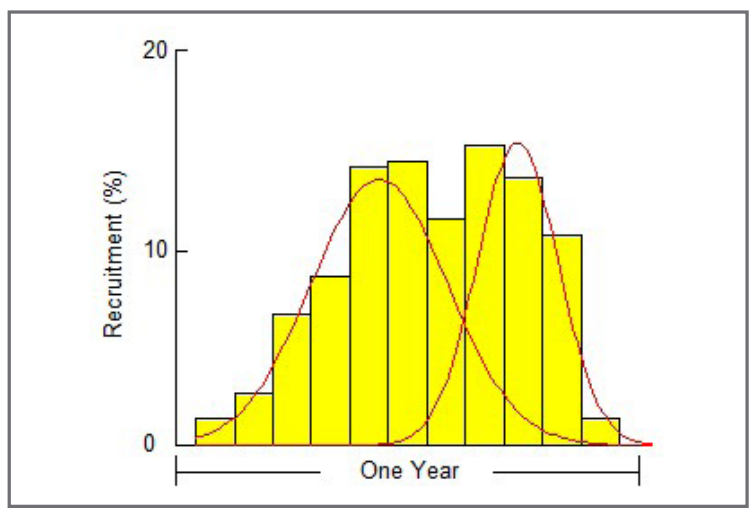

Figure 12B. Recruitment pattern for Decapterus macrosoma caught by ring net fishery in Camotes Sea from 2003-2012.

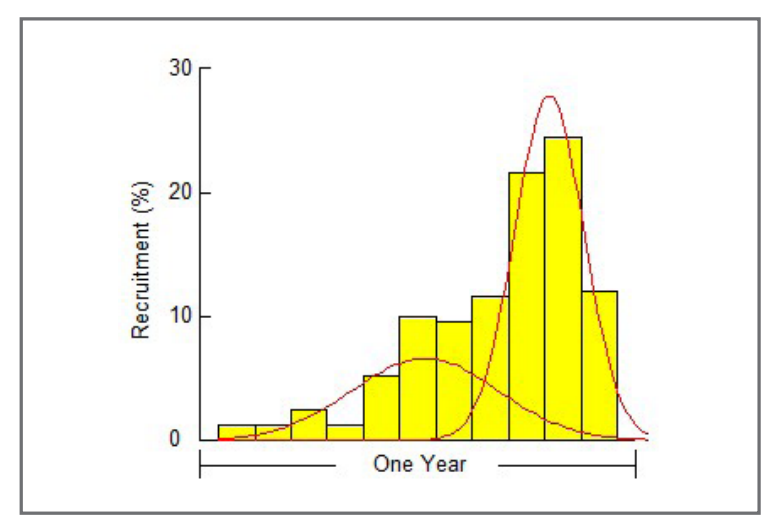

Figure 12C. Recruitment pattern for Selar crumenophthalmus caught by ring net fishery in Camotes Sea from 2003-2012.

on a monthly basis was obtained by computing the mean CPUE which is expressed in $\mathrm{kg} / \mathrm{hr}$.

There is a remarkable change in the overall trend of the catch of ring net fishery in the Camotes Sea from 1983 to 1987 (Jabat and Dalzell 1988) and in this study. Although the ring net fishery in the earlier study also showed a distinct seasonality, its production period peaked only once a year, particularly in June. The earlier catch was greatly influenced by the seasonal abundance of the bullet tuna ( $A$. rochei), which accounted for more than half of the catch during that period (Jabat and Dalzell 1988). On the contrary, the 2003-2012 trend seems to be influenced by the seasonal abundance of the small pelagic species of the Carangidae family which now dominate the catch.

\section{Species Composition and Seasonality}

There is a striking similarity in the seasonal patterns of production between the overall ring net fishery 
and the abundance of dominant species in the catch observed in the 1983-1987 and 2003-2012 assessments. Apparently, the catch trend is dictated and influenced by the seasonality of the major species abundantly caught throughout the entire period. However, there is a shift in the composition of dominant species caught. During the 1983-1987 assessment, the bullet tuna Auxis rochei comprised over $50 \%$ of the overall catch whereas in this study the Decapterus tabl accounts $28 \%$ of the total catch. The contribution of D. tabl to the CPUE trend is demonstrated by an increase in abundance and catch rates particularly in the peak months of February, April, and December. Other contributory species to the catch is D. macrosoma being abundant from March to June. The peak production of $S$. crumenophthalus which occurred in August to October is akin with the observation made by Jabat and Dalzell (1988) of similar species wherein higher catches were obtained once a year preferably from September and November only. Seasonal variation in the catch composition of pelagic species caught by ring net fishery in the Camotes Sea is very evident in both studies.

\section{Fish Size and Population Parameters}

The sizes of dominant species harvested from ring net fishery in the Camotes Sea are not only small compared with those commonly caught from Philippine waters but also much smaller than their maximum sizes. D. tabl, D. macrosoma, and S. crumenophthalmus appear to be more exploited as they were caught before reaching sexual maturity. Determination of exploitation rate of the top species also indicates high fishing pressure as revealed by high fishing mortality (F) and E values all exceeding the 0.5 threshold. For a stock to be optimally exploited, the fishing mortality should be about equal to natural mortality (Gulland 1971). Dalzell et al. (1987, cited in Jabat and Dalzell 1988) reported that the general pattern of small pelagic fish stocks in the Philippines shown to be severely overfished since the mid-1970's. High exploitation rate $(\mathrm{E})$ values may indicate unsustainable fishing as the fish are not given the chance to grow bigger and replenish the stock in the wild. Furthermore, the small pelagic in the Camotes Sea are not only vulnerable to ring net fishery but also by some other gears used in the area.

\section{Probabilities of Capture and Recruitment}

Comparison of overall mean lengths at first capture of dominant species, D. macrosoma, and $S$. crumenophthalmus, reveals a higher value in 2003-2012 than during the 1983-1987 study.

The recruitment patterns generated for $D$. macrosoma, S. crumenophthalmus, and D. kurroides follows two major modes of recruitment for each year. The recruitment occurs in the beginning, middle, or towards the end of the year. This finding is in conformity with the results of Jabat and Dalzell (1988) where there was also a bimodal pattern of recruitment revealed for most of the small pelagic species in the catch of the ring net fishery from the Camotes Sea and in the Philippines in general. The seasonality of dominant species caught is also influenced by the mode of recruitment it exhibits.

\section{SUMMARY AND RECOMMENDATION}

Results of the ten-year data monitored from 2003-2012 in the Camotes Sea using ring net recorded a total of 59 species belonging to 8 families and 4 unidentified. The five dominant species in the catch by weight are pelagic type, namely $D$. tabl, D. macrosoma, S. crumenophthalmus, D. kurroides and M. maculata altogether comprising $77 \%$ of the overall landed volume.

Population parameters such as growth, mortality, probability of capture, recruitment, and exploitation rate (E) of the abundantly caught species were estimated using the length frequency data, which were processed and analyzed using the FISAT program developed by FAO/ ICLARM tool.

Generally, the sizes of the commonly caught fishes were smaller than the maximum sizes which can be attained by the species and were harvested before reaching maturity lengths.

Total mortality, fishing mortality, and exploitation rate (E) of three major species D. macrosoma ( $\mathrm{E}=0.71)$, S. crumenophthalmus $(\mathrm{E}=0.68)$, and D. kurroides $(\mathrm{E}=0.51)$ were determined and revealed consistently higher E values which were mainly attributed to higher fishing mortality compared with the earlier study of Jabat and Dalzell (1988). The exploitation levels obtained for the three species exceeded the 0.5 threshold, which suggests growth overfishing. This may also indicate that half or more of the biomass per recruit seems to be exploited by the fishery. The stock in the Camotes Sea is not just vulnerable to ring net fishery but also to other gears targeting pelagic and demersal species.

There is a need to continuously assess the stocks in the Camotes Sea considering that they are highly seasonal as shown in the shift of dominant species in the catch between the 1983-1987 and 2003-2012 assessments, and to document any changes in the seasonal abundance of catch.

Reproductive biological study of the top dominant species is recommended to be the next researchable area in order to substantiate the present results and, eventually, proper measures for sustainable management of these species can be imposed.

\section{R E F E R E N C E S}

Dalzell P, Ganaden R. 1987. A Review of the Fisheries for small Pelagic Fishers in the Philippine Waters. BFAR Technical paper series 10(1). BFAR and International Center for Living Aquatic Resources Management., Manila, Philippines. p. 54

Dalzell P, Corpuz P, Ganaden R, Pauly D. 1987. Estimation of maximum sustainable yield and maximum economic rent from the Philippines small pelagic fisheries. Bureau of Fisheries and Aquatic Resources 
Tech.Pap.Ser. X(3):23.

Gayanilo FC. Jr., Pauly D. 1997. FAO-ICLARM Stock Assessment Tools (FiSAT), Reference Manual, International Center for Living Aquatic Resources Management, Rome. p. 219

Gulland JA, editor. 1971. The fish resources of the ocean. Fishing News Books. West Byfleet, Surrey, England.

Jabat M, Dalzell P. 1988. Preliminary Stock Assessment of Danao Ring Net Fishery for small pelagic fishes in Camotes Sea.

Luchavez JA, Abrenica B.T. 1997. Fisheries Profile of Bais Bay, Negros Oriental. Silliman Journal 37(3-4): 93102.
Pauly D. 1980. On the interrelationships between natural mortality growth parameters and mean environmental temperature in 175 fish stocks. ICES Journal of Marine Science 39(2): 175-192. https:// doi.org/10.1093/icesjms/39.2.175

Pauly D. 1984. Length Converted catch curve: a powerful tool for fisheries research in the tropics (part II). International Center for Living Aquatic Resources Management contribution no. 173

Wetherall JA, 1986. A new method for estimating growth and mortality parameters from length-frequency data. ICLARM Fishbyte 4(1): 12-14. 